\title{
A Soy Protein-Based Composite Film with a Hierarchical Structure Inspired by Nacre
}

\author{
Yecheng Xu${ }^{1}$, Chaojie Xu${ }^{1}$, Mingsong Chen ${ }^{1}$, Jianzhang $\mathrm{Li}^{1}$, Ling Zeng ${ }^{2}$, Jing Luo ${ }^{3}$, Qiang Gao ${ }^{1, *}$ and \\ Sheldon Q. Shi ${ }^{4, *}$
}

${ }^{1}$ Beijing Key Laboratory of Wood Science and Engineering \& MOE Key Laboratory of Wooden Material Science and Application, Beijing Forestry University, Beijing, 100083, China

${ }^{2}$ Nanning SCISKY Waterborne Technologies Co., Ltd., Nanning, 530105, China

${ }^{3}$ College of Materials Science and Engineering, Nanjing Forestry University, Nanjing, 210037, China

${ }^{4}$ College of Engineering, Department of Mechanical and Energy Engineering, University of North Texas, Denton, 76207-7102, USA

*Corresponding Authors: Qiang Gao. Email: gaoqiang@bjfu.edu.cn; Sheldon Q. Shi. Email: Sheldon.Shi@unt.edu

Received: 30 July 2021 Accepted: 16 August 2021

\begin{abstract}
Soy protein-based composite film is a potential replacement for petroleum-based film with multipurpose applications and cleaner production. It is difficult to improve both the tensile strength and toughness of a protein-based film without sacrificing its elongation. In this study, inspired by the hierarchical structure of nacre, a facile yet delicate strategy was developed to fabricate a novel bio-based film with excellent toughness and high strength. Triglycidylamine (TGA) crosslinked soy protein (SPI) as hard phase and thermoplastic polyurethane elastomer (TPU) as soft phase comprise an alternative lay-up hierarchical structure. The interface of these two phases is enhanced using triglycidylamine (TGA) surface-modified TPU (MTPU). The tensile strength of SPI/MTPU/TGA films increases by $392 \%$ to $7.78 \mathrm{MPa}$ and their toughness increases by $391 \%$ to $8.50 \mathrm{MJ} / \mathrm{m}^{3}$ compared to soy protein/glycerol film. The proposed hierarchical structure can also be extended to other high-performance materials and polymers.
\end{abstract}

\section{KEYWORDS}

Soy protein-based composite film; hierarchical structure; TPU; enhancement mechanism

\section{Introduction}

Many researchers have recently investigated the use of bio-based composites to replace conventional petroleum-based materials [1-6]. Among all bio-based materials, soybean protein isolate (SPI), a renewable by-product of the soybean oil industry, is biodegradable, easily processed, and biocompatible [7]. These qualities make SPI a strong candidate for bio-adhesive, film, and hydrogel products $[3,8,9]$. Soy protein is a viable renewable resource for producing environmentally safe and cleaner industrial products [10]. However, composite films processed from pure soy protein are brittle due to the strong intra-/intermolecular interactions among soy protein molecules [11]. Adding small molecular plasticizers, such as hydroxylamine and polyols glycerol [12], can reduce the intra-/intermolecular interactions among soy protein molecules and increase the mobility of the protein chains, thus reducing the brittleness of soy 
protein composite films. Nontoxic and water-soluble organic plasticizer-glycerol was usually used in SPI. However, the inherent hydrophilicity and increased pliability of SPI/glycerol films remit poor mechanical strength and low water resistance [3]. In addition, glycerol in the protein matrix easily migrates outward under thermodynamic effect, which limits the application of these composite materials.

Many attempts have been made to improve the mechanical properties of SPI composite films [13]. For instance, Bozaci et al. [14] incorporated virgin coconut oil (VCO), a hydrophobic component with strong oxidative stability, into SPI films to form block copolymerization. Scherr et al. [15] crosslinked thiolated polyglycerol dendrimer films on gold, which self-perforates upon transfer to holey carbon substrates, forming a sub-micron-sized hydrogel network with enhanced mechanical properties. These additives react with the functional groups (e.g., amino, hydroxyl, carboxylic) on proteins to form a crosslinking network that significantly improves the mechanical strength and water resistance of the resultant composite films. However, this method compromises the film's toughness and elongation at break. It is necessary to develop an environmentally friendly plasticizer that yields flexible and stretchable bio-based composites film without compromising their strength [16].

Nacre has a "brick-mortar" structure assembled from aragonite and organic alternating layers exhibiting exceptional hardness, toughness, thermo stability, and barrier effect [17,18]. "Bricks" of mineral polygonal tablets with 200-500 $\mathrm{nm}$ thickness and 5-10 $\mathrm{mm}$ diameter as mesocrystals were assembled from nanograins with organic materials in this study as shown in Fig. 1b [19]. This highly complex, delicate, multi-scale, multi-level assembly structure has favorable mechanical properties. The "mortar" in this case is the protein matrix (Fig. 1c) [19], which includes different organic components such as chitin and lustrin A [20]. Frequent crack deflection between the two phases during fracture of the nacre, in addition to the aragonite tablet, toughen the material. This hierarchical structure of alternating soft and hard phases has very high strength and toughness. Bulletproof glass is another noteworthy example of a similar strong, tough hierarchical structure [21]. Inspired by the structural qualities of nacre, soybean protein membranes with a hierarchical structure were designed in this study to improve the mechanical properties, water resistance, and toughness of soy protein composite films.

(a)

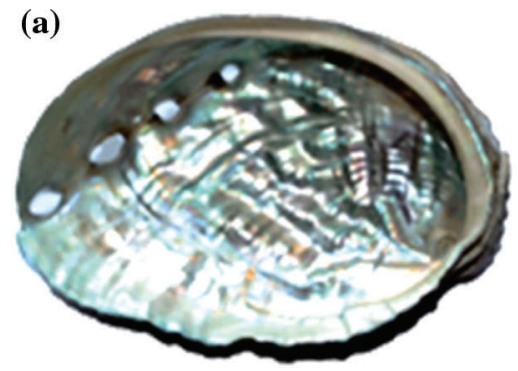

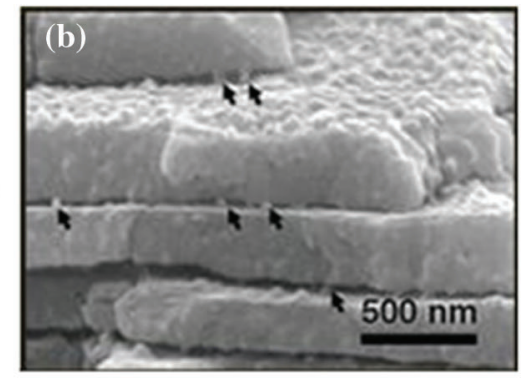

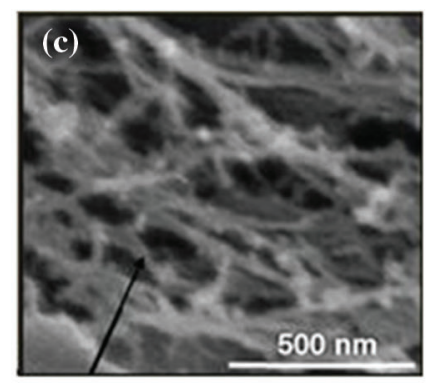

Figure 1: Natural nacre (a) digital image of abalone nacre. (b) $95 \mathrm{vol} \% \mathrm{CaCO}_{3}$ platelets assembled into layered structure. (c) $5 \mathrm{vol} \%$ protein and chitin bond $\mathrm{CaCO}_{3}$ platelets. Reproduced from reference [19]

Thermoplastic polyurethane elastomer (TPU) is a block copolymer composed of isocyanate (curing agent), macromolecular polyether or polyester glycol (constituting the soft segment backbone), and polyhydric alcohol or amine a as chain extender (or hard segment structure). TPU has many advantages [22] including high abrasion and chemical resistance, adjustable mechanical properties and biodegradation rate, and strong blood and tissue compatibility [23,24]. Many researchers have used TPU to toughen existing materials and develop new composite materials. For instance, Boyd et al. [25] improved the delamination resistance and durability of structural composite laminates with TPU interlayers that allow decoupling the structural plies within the laminate, thus preventing catastrophic 
delamination. The TPU molding process is simple and allows for the fabrication of products with various shapes, and therefore has been utilized throughout automotive, transportation, textile, petrochemical, building construction, shipbuilding, mechanical engineering, electronic information, medical, and military industries [26,27]. TPU, as a simple, clean and nontoxic additive, can improve the toughness of soybean protein films and reduce the amount of chemical additives necessary to fabricate them.

In our strategy, soy protein is crosslinked by a self-synthesized eco-friendly crosslinker, epoxide (TGA), as hard phase and thermoplastic elastomer TPU as soft phase to produce a novel hierarchical composite film. TPU is surface-modified by TGA to enhance the interface between the TPU and soy protein matrix and prevent delamination. The effect of the hierarchical structure on the performance of the soybean protein membrane was evaluated in terms of thermo stability, morphology, mechanical properties, and microstructure by comparison against unmodified film. Both the tensile qualities and toughness of the protein-based film improved without any reduction in elongation after engineering the hierarchical structure. Further, plasticizer does not migrate outward from the proposed film due to the hydrophobicity of TPU. Building a hierarchical structure with an obvious soft and hard phase can improve the performance and toughness of other composite materials and polymers as well. In summary, a simple, effective, and environmentally friendly strategy was established in this study for substantial enhancement of bio-based film performance.

\section{Experimental Procedures}

\subsection{Materials}

SPI (95\% protein) was provided by Yu Wang Ecological Food Industry Co., Ltd. (Shandong, China). Commercial TPU was purchased from Kexin Polymer Materials Co., Ltd. (Kunshan, China). Glycerol (99\% pure), N, N-dimethylformamide, and sodium hydroxide were obtained from Beijing Chemical Reagents Co., Ltd. (Beijing, China) and used without further purification.

\subsection{Preparation of the $T G A$}

TGA was synthesized by reacting epichlorohydrin with ammonia [28]. Epichlorohydrin and aqueous ammonia were mixed in a three-necked flask with a mole ratio of $3: 1$, then the resulting mixture was reacted from $50^{\circ} \mathrm{C}$ to $65^{\circ} \mathrm{C}$ and stirred for about $2 \mathrm{~h}$ until the temperature stabilized. A condenser tube was installed on the three-port flask to maintain a stabilized temperature. The residual epichlorohydrin and ammonium hydroxide were removed by vacuum distillation, resulting in a colorless syrup consisting mostly of tris(3-chloro-2-hydroxypropyl) amine. Finally, sodium hydroxide solution (50\%) was added to the syrup for $2 \mathrm{~h}$ at $20^{\circ} \mathrm{C}$ to induce epoxy ring closure. The precipitate of sodium chloride was filtered off, then the residue was vacuum distilled to obtain pure viscous TGA. The reaction pathway is shown in Scheme 1.

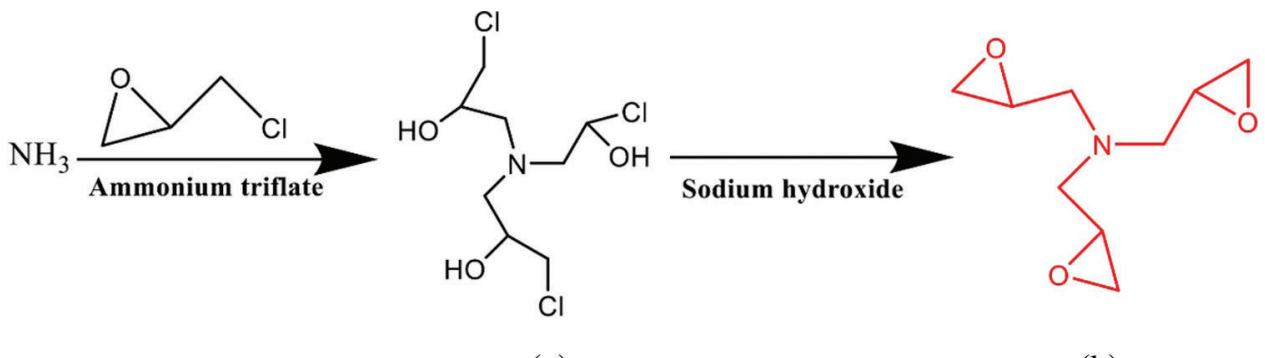

(a)

(b)

Scheme 1: Synthesis of TGA 


\subsection{Preparation of the MTPU}

MTPU was synthesized based on the epoxy crosslinker (TGA) and TPU. TGA and TPU with a mole ratio of $4: 1$ were placed into a three-necked flask equipped with a condenser and stirrer. The resulting mixture was continuously stirred for $2 \mathrm{~h}$ at $60^{\circ} \mathrm{C}$ in a constant temperature water bath to make the amino group in the TPU react with the epoxy group on the epoxy crosslinking agent. The mixture was filtered with hydrogen peroxide using a glass sand core filter device, then residual epoxy crosslinking agents were removed. Finally, the epoxidized TPU solution was freeze-dried to obtain MTPU in the form of a light white powder.

\subsection{Characterization of TPU and MTPU}

For ${ }^{1} \mathrm{H}$ NMR analysis, TPU or MTPU $(30 \mathrm{mg})$ was dissolved in $\left(\mathrm{DCON}\left(\mathrm{CD}_{3}\right)_{2}\right)$ and spectra were acquired on a 300-MHz JEOL ECS-400 spectrometer (Japan) over an acquisition time of $3.0 \mathrm{~s}$ [29].

\subsection{Preparation of SPI Films}

SPI-based films were prepared via a two-step casting method [30]. First, SPI (5 g) and distilled water $(95 \mathrm{~g})$ were sequentially added to a $250 \mathrm{~mL}$ beaker and stirred for $30 \mathrm{~min}$. The $\mathrm{pH}$ of the protein dispersion was adjusted with a $10 \%$ sodium hydroxide solution to $9 \pm 0.1$ and then heated in a water bath at $85^{\circ} \mathrm{C}$ for an additional $30 \mathrm{~min}$. TPU and MTPU powders were dissolved in N, N-dimethylformamide solution to obtain a $10 \%$ transparent solution, which was added to the above protein dispersions separately. A certain amount of glycerol, TPU, or MTPU (as listed in Tab. 1) was dispersed in the SPI solution while the mixture was constantly stirred. To form a more homogeneous composite, the SPI/ glycerol, SPI/TPU, or SPI/MTPU solutions were sonicated for $20 \mathrm{~min}$. The resulting mixtures were then poured into Teflon plates and dried at $60^{\circ} \mathrm{C}$. Finally, the films were placed in a saturated $\mathrm{K}_{2} \mathrm{CO}_{3}$-regulated desiccator (approximately 50\% relative humidity).

Table 1: Formulations of SPI-based films

\begin{tabular}{ll}
\hline Sample & SPI-based film formulation \\
\hline SPI/glycerol & SPI $(5 \mathrm{~g})$; glycerol $(3 \mathrm{~g})$; Deionized water $(95 \mathrm{~g})$ \\
SPI/TPU & SPI $(5 \mathrm{~g})$; TPU $(3 \mathrm{~g})$; Deionized water $(95 \mathrm{~g})$ \\
SPI/TPU/TGA & SPI $(5 \mathrm{~g})$; TPU $(3 \mathrm{~g})$; Deionized water $(95 \mathrm{~g})$; TGA $(1 \mathrm{~g})$ \\
SPI/MTPU & SPI $(5 \mathrm{~g})$; MTPU $(3 \mathrm{~g})$; Deionized water $(95 \mathrm{~g})$ \\
SPI/MTPU/TGA & SPI $(5 \mathrm{~g})$; MTPU $(3 \mathrm{~g})$; Deionized water $(95 \mathrm{~g})$; TGA $(1 \mathrm{~g})$ \\
\hline
\end{tabular}

2.6 Characterizations of TPU, MTPU, SPI-Based Films

2.6.1 Fourier Transform Infrared (FTIR) Spectroscopy

The TPU, MTPU, and modified soy protein-based films were cured completely and ground into powder. FTIR analyses were conducted on a Nicolet 7,600 spectrometer (Nicolet Instrument Corporation, Madison, WI) with a potassium bromide crystal. The spectra were recorded within a range of $650 \mathrm{~cm}^{-1}-400 \mathrm{~cm}^{-1}$ with 32 scans.

\subsubsection{Thermogravimetric Analysis (TGA)}

The thermal stabilities of the TPU, MTPU, TGA, and cured films were measured on a TGA instrument (TA Q50, WATERS Company, USA). Approximately 3-8 $\mathrm{mg}$ of powdered film samples were weighed and scanned from $25^{\circ} \mathrm{C}$ to $610^{\circ} \mathrm{C}$ at a heating rate of $10{ }^{\circ} \mathrm{C} / \mathrm{min}$ in a nitrogen environment [31]. The weight changes were recorded throughout. 


\subsubsection{Scanning Electron Microscopy (SEM)}

A SEM analyzer (FEI Quanta FEG650) with an accelerating voltage of $10 \mathrm{kV}$ was used to observe the surface morphology of the samples. The section morphology of the SPI films was analyzed after applying liquid nitrogen embrittlement to obtain flat sections.

\subsubsection{Atomic Force Microscopy (AFM)}

Atomic force microscopy (AFM, Bruker Multimode 8) was used to observe the surface morphologies of SPI-based films in order to verify the microphase separation structure of the prepared soybean protein composite film. A phase diagram of the sample was obtained on a Bruker-type atomic force microscope in the tapping mode so that changes in different surface areas could be observed. The DMT elastic modulus of the soy protein films was tested in peak force tapping quantitative nanomechanical mode to characterize the soft and hard surfaces of the protein films. The degree of difference was determined between the soft and hard phase structures.

\subsection{Mechanical Performance}

The mechanical properties of the films were measured at room temperature on a universal testing machine (Instron 3365, Norwood, MA) equipped with a $100 \mathrm{~N}$ load cell. The specimen dimensions were $10 \mathrm{~mm} \times 80 \mathrm{~mm}$ with a $50 \mathrm{~mm}$ gauge length. The thicknesses of films (five replicates) were measured with a digimatic micrometer. The tensile strength (TS) and elongation at break (EB) of each film were determined as per the mean value of six replicates.

\section{Results and Discussion}

\subsection{Analysis of TGA, TPU, MTPU}

Fig. 2a shows the FTIR spectra of TGA, TPU, and MTPU. For TGA, the absorption peaks at 2,956, $1,427,1,302,1,202,1,050,881$ and $744 \mathrm{~cm}^{-1}$ were attributed to $-\mathrm{CH}_{3}$ absorption, $\mathrm{C}=\mathrm{O}$ stretching, isopropyl, $\mathrm{O}-\mathrm{C}-\mathrm{O}$ stretching, the substituted aromatic, epoxy group, and out-of-plane deformation of the carbonate group, respectively [28]. The peaks at $881 \mathrm{~cm}^{-1}$ and $913 \mathrm{~cm}^{-1}$ of TGA spectrum were attributed to the epoxy group. In the MTPU spectrum, the intensity of the $-\mathrm{CH}_{2}-,-\mathrm{CH}_{3}$ and $\mathrm{C}-\mathrm{N}$ stretching vibration peak increased and the peak of epoxy group was comparable with that of TPU, indicating successful TGA grafting on TPU (Fig. 2d).

Fig. 2b shows the TG and DTG curves of TPU and MTPU. After grafting TGA, the peak thermal degradation temperature of MTPU reached $345.8^{\circ} \mathrm{C}$, which was higher than that of TPU at $319.6^{\circ} \mathrm{C}$; the new structure formed by TGA grafting showed higher thermal stability. This can be attributed to the high carbon content of TGA and the formation of a different structure. The structure and surface modification process of TPU were also examined by ${ }^{1} \mathrm{H}$ NMR spectroscopy (Fig. 2c). In the ${ }^{1} \mathrm{H}$ NMR spectrum of TPU, the proton signals of the solvent were located at $2.47 \mathrm{ppm}$ (peak 1), whereas the numerous strongintensity signals at $1.19 \mathrm{ppm}$ (peak 2) were attributable to methyl $\left(-\mathrm{CH}_{3}\right)$ protons. Finally, signals at 3.32 ppm (peak 3) and 7.13 ppm (peak 4) were thought to methylene $\left(-\mathrm{CH}_{2}-\right)$ protons and $\mathrm{N}-\mathrm{H}$ protons. As shown in the figure, the methylene $\left(-\mathrm{CH}_{2}-\right)$ protons of MTPU increased and the N-H protons of MTPU decreased compared with TPU, indicating that TGA was successfully grafted on TPU to form MTPU.

\subsection{Performance of SPI-Based Films}

Fig. 3a shows the FTIR spectra of films. The amide bond distribution of SPI/glycerol film is shown in Tab. 2. The broad band at $3,325 \mathrm{~cm}^{-1}$ corresponds to the bending vibration of the free and bound $\mathrm{N}-\mathrm{H}$ and $\mathrm{O}-\mathrm{H}$ groups, which formed hydrogen bonds with the carbonyl group on the peptide bond in the protein. The characteristic peak observed at $2,931 \mathrm{~cm}^{-1}$ can be attributed to the stretching vibration of methylene $\left(-\mathrm{CH}_{2}-\right)$ [32]. 


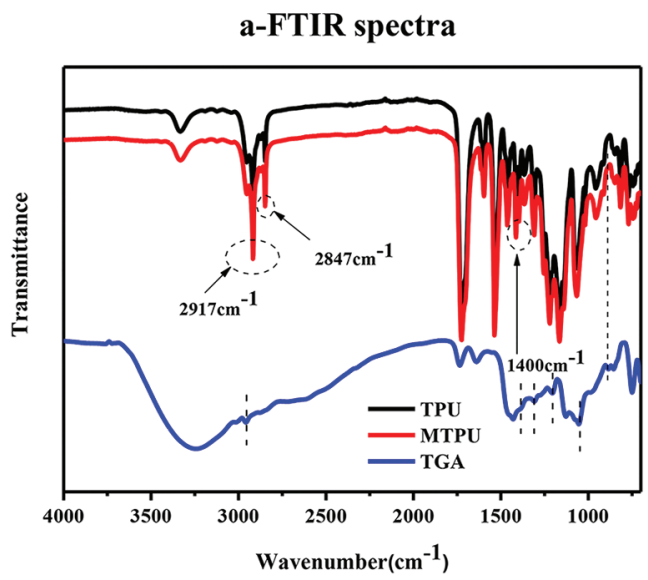

c-1'H NMR spectra

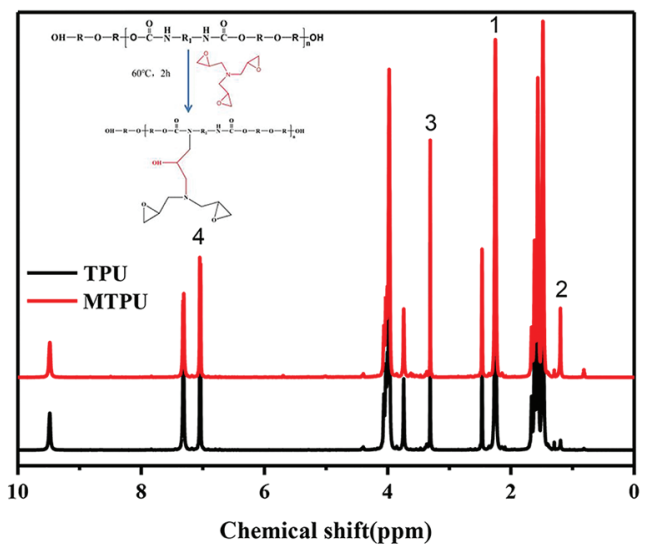

b-TG and DTG curves

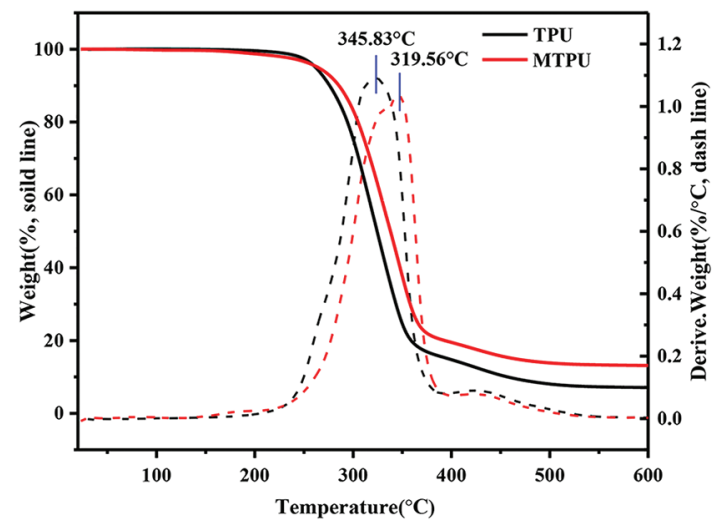

d-Schematic synthesis of MTPU

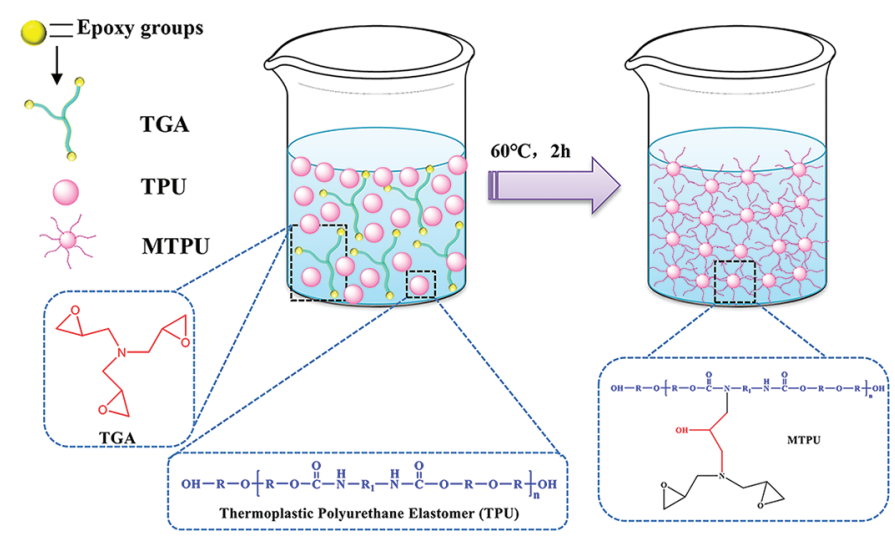

Figure 2: (a) FTIR spectra of TGA, TPU, and MTPU; (b) TGA and DTG curves of TPU and MTPU; (c) ${ }^{1} \mathrm{H}$ NMR spectrum of TPU and MTPU; (d) Synthesis of MTPU

a-FTIR spectra

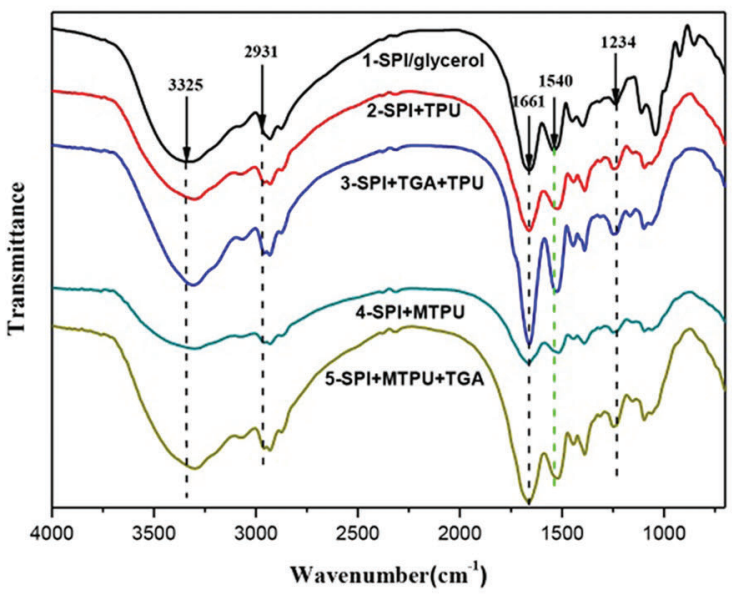

b-TG and DTG curves

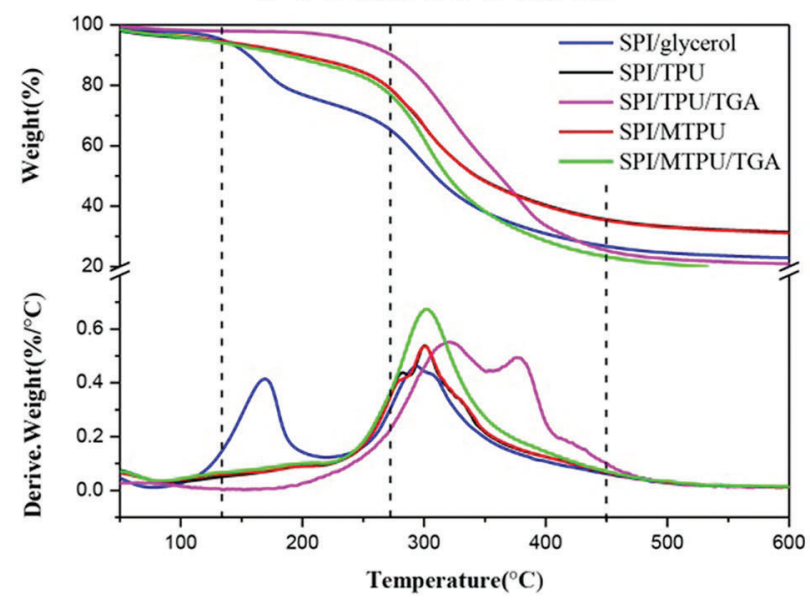

Figure 3: FTIR and TG/DTG curves of films 
Table 2: Characteristic peaks for SPI-based films

\begin{tabular}{lll}
\hline Amide bond & Wavenumber $\left(\mathrm{cm}^{-1}\right)$ & Group characteristic peak \\
\hline Amide I & 1,661 & $\mathrm{C}=\mathrm{O}$ stretching \\
Amide II & 1,540 & $\mathrm{~N}-\mathrm{H}$ bending \\
Amide III & 1,234 & $\mathrm{~N}-\mathrm{H}$ stretching and $\mathrm{C}-\mathrm{N}$ stretching \\
\hline
\end{tabular}

For SPI/TPU film, the ester bond characteristic peaks of TPU appeared at $1,731 \mathrm{~cm}^{-1}$, indicating that TPU was uniformly dispersed in the SPI film. Compared to SPI/glycerol films, no new peaks were detected in the spectrum of the SPI/TPU films, indicating that SPI and TPU were physically blended without chemical reaction or bond formation. Incorporating TGA did not change the intensity of Amide I between SPI/TPU/TGA films and SPI/TPU films. Therefore, compared with SPI/TPU films and the SPI/TPU/TGA film based on the Amide I, the Amide II (N-H) peak of SPI/TPU/TGA films decreased and a blue shift occurred; the epoxy group of TGA reacted with the protein active group $(-\mathrm{NH} 2,-\mathrm{NH}-)$ to form a crosslinking network (Fig. 4a).

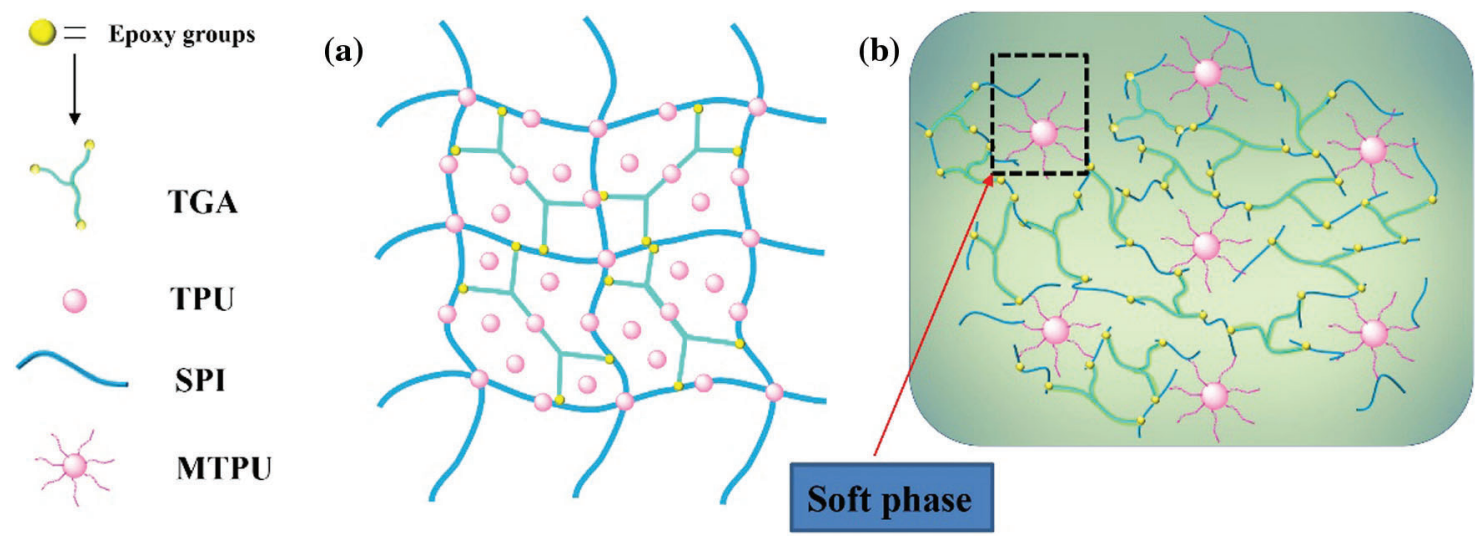

Figure 4: Cross-linking of (a) SPI/TGA/TPU adhesive and (b) SPI/MTPU/TGA adhesive

In comparison with SPI/TPU films, based on the intensity of the amide I peak, the N-H peak decreased and the $\mathrm{C}-\mathrm{N}$ peak of the SPI/MTPU film significantly increased. The Amide II blue shifted, indicating that the epoxy group of MTPU reacted with the active groups $\left(-\mathrm{NH}_{2},-\mathrm{NH}-\right)$ in the protein. In this process, TPU was connected with SPI by TGA to form a hierarchical structure with alternating soft and hard phases (Fig. 4b). However, the SPI matrix was not strong enough to form a hard phase. To enhance the hard phase in the hierarchical adhesive, epoxy crosslinking agent TGA was added again to crosslink proteins. Compared with SPI/MTPU films, the Amide I and Amide II of SPI/MTPU/TGA films show no obvious changes while the Amide III significantly gained intensity, indicating that the addition of TGA strengthened the $\mathrm{C}-\mathrm{N}$ stretching vibration peak. Therefore, the epoxy cross-linker TGA was used as the bridge linked MTPU with the crosslinked protein to form a hierarchical structure with obvious alternative lay-up of soft and hard phases.

Fig. $3 b$ shows the TG/DTG curves of films. The SPI/glycerol film underwent three degradation stages: dehydration reaction from 20 to $130^{\circ} \mathrm{C}$, glycerol degradation from 130 to $270^{\circ} \mathrm{C}$, and backbone peptide degradation from 270 to $450^{\circ} \mathrm{C}$ [33]. After TPU addition to SPI, two degradation peaks appeared at $280.5^{\circ} \mathrm{C}$ and $300.9^{\circ} \mathrm{C}$ due to incompatibility between TPU and the SPI protein dispersion. After adding TPU and TGA together, the epoxy group in TGA reacted $\left(-\mathrm{NH}_{2},-\mathrm{NH}-\right)$ in protein to form a stable chemical connection, while the TPU was dispersed homogeneously in the crosslinked network to form an interpenetrating network structure. The degradation peak of SPI/TPU/TGA film moved to 319.5 and $384.8^{\circ} \mathrm{C}$, indicating that the thermal stability of the SPI/TPU/TGA film improved over that of SPI/TPU 
films. For SPI/MTPU films, the degradation peaks merged into one peak at $301.6^{\circ} \mathrm{C}$, which was attributed to the synthesized MTPU reacting with SPI form a hierarchical structure with hard and soft phases. However, when TGA was added into SPI/MTPU film (SPI/MTPU/TGA film), the degradation peak moved to $305.9^{\circ} \mathrm{C}$ and became higher than that of the SPI/MTPU film, indicating that TGA linked with SPI to form a hierarchical structure with enhanced hard phases and an integrated cross-linked structure.

\subsection{Mechanical Properties of SPI-Based Films}

A series of SPI-based composite films were fabricated to investigate the effects of TPU on their mechanical properties (Figs. 5a-5d). The SPI/glycerol films exhibited extremely low strength and toughness at $1.58 \mathrm{MPa}$ and $1.73 \mathrm{MJ} / \mathrm{m}^{3}$ (curve 1), respectively, with an elongation at break of $202.7 \%$. The addition of glycerol appears to have formed weak hydrogen bonds with SPI resulting in relatively low strength and toughness. SPI/TPU composite films (curve 2) showed an obvious increase in tensile strength, from 1.58 to $8.25 \mathrm{MPa}$ compared with the SPI/glycerol films, due to the high strength of TPU itself and the formation of a layered structure with protein. However, the toughness and elongation at break of the SPI/glycerin films were only $1.28 \mathrm{MJ} / \mathrm{m}^{3}$ and $17.3 \%$, respectively, which can be attributed to the brittleness of SPI and delamination between SPI and TPU. In other words, an improvement in the toughness of the film decreased its tensile strength.
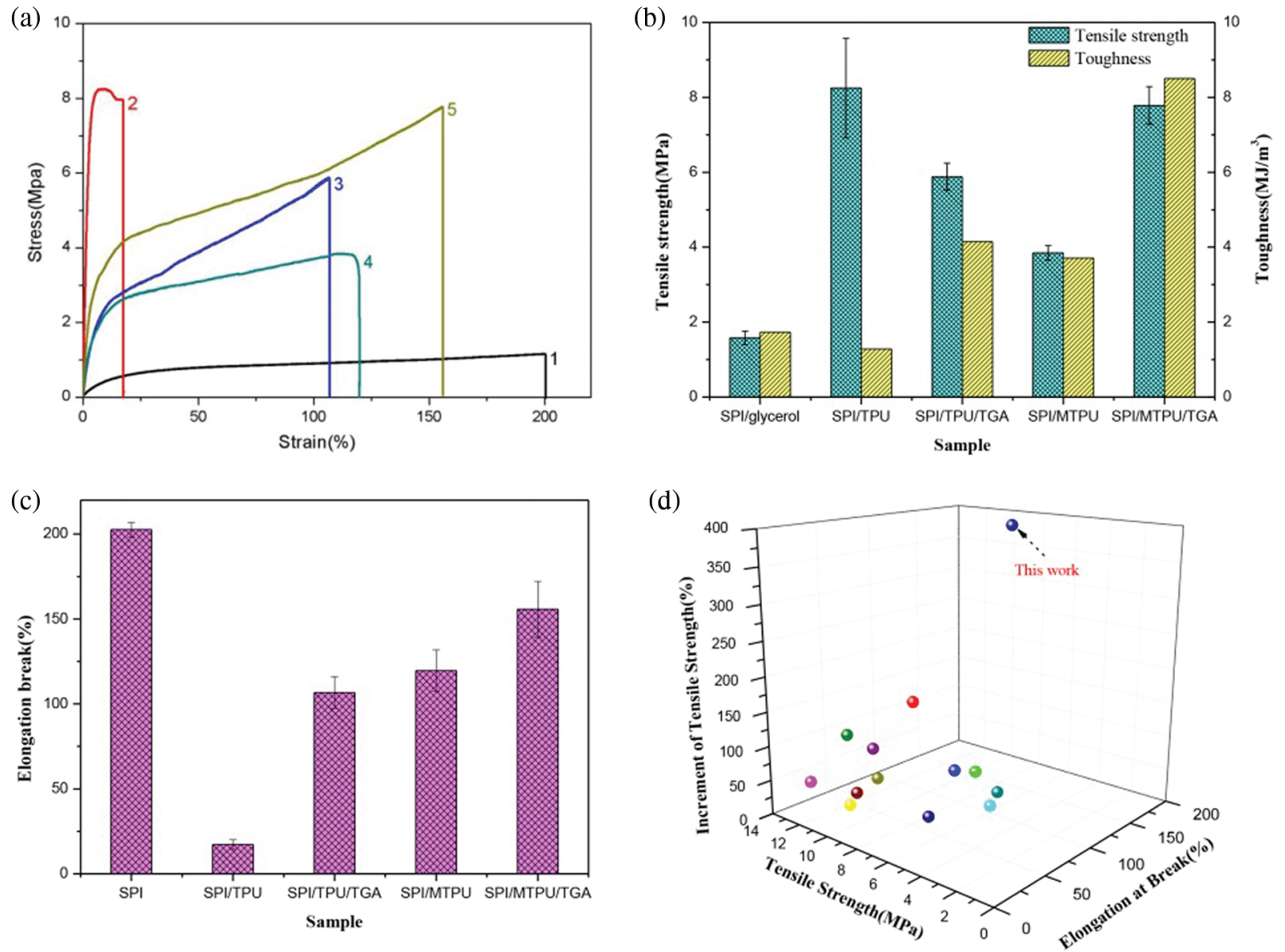

Figure 5: (a) tensile stress-strain curves of neat SPI/glycerol films (curve 1), SPI/TPU films (curve 2), SPI/TPU/TGA films (curve 3), SPI/MTPU films (curve 4), SPI/MTPU/TGA films (curve 5); (b) tensile strength and toughness of SPI films, (c) elongation at break of SPI films, (d) tensile strength, elongation at break, and incremental tensile strength of SPI-based films and other reported SPI-based films [30,34-44] 
As expected, after the addition of TGA (curve 3), SPI/TPU/TGA films showed good stretchability (elongation at break of 106.7\%) and an obvious increase in toughness $\left(4.15 \mathrm{MJ} / \mathrm{m}^{3}\right)$ compared with the SPI/TPU films. The epoxy groups in the crosslinking agent TGA reacted with active groups in soybean protein molecules to generate a crosslinked structure and hard phase in the film. TPU was interwoven into the cross-linking structure to form an interpenetrating network structure as a soft phase which completed the hierarchical structure with alternating soft and hard phases, thus improving the toughness of the films. However, the tensile strength of SPI/TPU/TGA films were recorded at $5.88 \mathrm{MPa}$, which is $29 \%$ lower than that of SPI/TPU films. The reduction in tensile strength may be due to delamination between the crosslinked SPI and TPU.

TPU was grafted by TGA and mixed with SPI to develop SPI/MTPU films with enhanced interfacial bonding between the soft and hard phases (curve 4). The epoxy group on MTPU reacted with the active group in the protein $\left(-\mathrm{NH}_{2},-\mathrm{NH}-\right)$ to form a hierarchical structure. Compared with SPI/TPU films, the strength and toughness of SPI/MTPU films improved by $143 \%$ and $114 \%$ to $3.85 \mathrm{MPa}$ and $3.71 \mathrm{MJ} / \mathrm{m}^{3}$, respectively. The elongation at break of SPI/MTPU films was $119.7 \%$ higher than that of SPI/TPU films. After the addition of TGA (curve 5) to the SPI/MTPU films, the toughness and elongation at break further increased to $8.50 \mathrm{MJ} / \mathrm{m}^{3}$ and $155.7 \%$, respectively. The tensile strength of SPI/MTPU/TGA films was 7.78 MPa, marking a 32.3\% increase over SPI/MTPU films and a $392.0 \%$ increase over SPI/glycerol films. This improvement is attributable to the construction of a hierarchical structure with soft and hard phases as well as improvement in the interface between soft and hard phases having formed an integrated cross-linked structure.

Fig. 5d compares the tensile strength and elongation at break of SPI/MTPU/TGA films with other SPI-based complex films. The SPI/MTPU/TGA films show much better breaking strain properties than other SPI-based composites films, which indicates that an integrated hierarchical cross-linked structure with alternating soft/hard phases benefits both tensile strength and toughness.

\subsection{Microstructures of Films}

Fig. 6a shows the fracture surfaces of soybean protein composite films at 1,000 times magnification. For SPI/glycerol films, the cross-section showed a relatively smooth and continuous fracture surface during the crack growth process, which was mainly caused by the brittleness of the protein matrix itself [45]. An irregular rough strip structure was observed in the SPI/TPU films, which signifies relatively weak interface interaction between SPI and TPU due to the simple physical combination without any reaction. A strip-like structure was also observed in the cross-sections of SPI/MTPU composite films, however, it was more uniform and denser than that of SPI/TPU films. Thus, the epoxy crosslinker was successfully grafted onto the TPU. The epoxy group in the MTPU reacted with SPI to reduce delamination between SPI and TPU, which showed a small strip structure. After adding TGA into SPI/TPU films, the crosssection became more compact and rougher compared with the SPI/TPU films. To this effect, TGA reacted with SPI to form a cross-linked structure, while the TPU uniformly penetrated into the crosslinked SPI to form rough but uniform cross-sections. A similar but rougher section was observed in the SPI/MTPU/ TGA film, indicating that the crosslinked SPI connected with MTPU to form a hierarchical structure with alternating soft and hard phases. In the film formulation, TGA enhanced the hard phase of the hierarchical structure to create visibly distinguishable layers and reinforced performance in the film. MTPU enhanced the chemical bonds between crosslinked SPI and TPU, which further enhanced the interfacial interaction between the two phases to prevent delamination. 
(a)

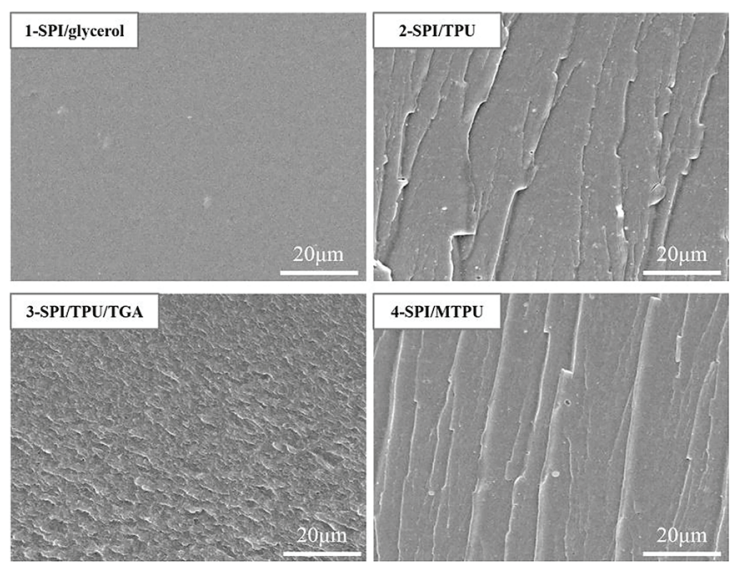

(b)

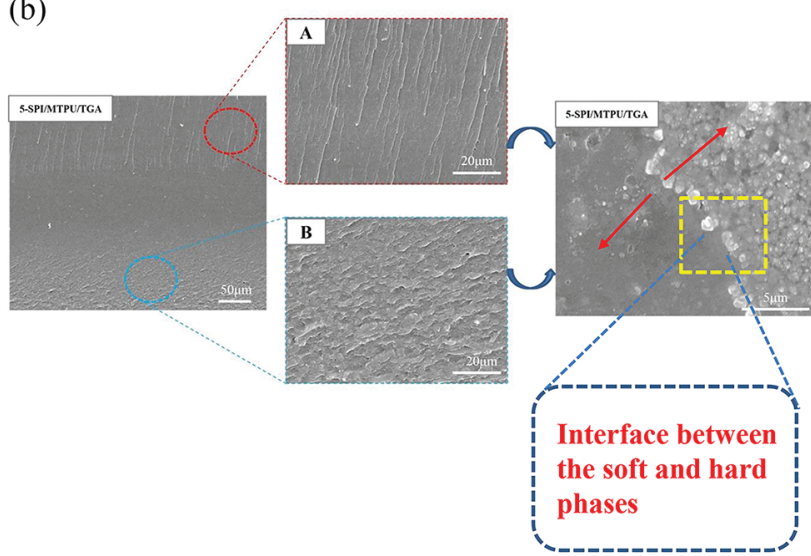

Figure 6: (a) cross-sectional SEM images of SPI films and (b) SEM images of SPI/MTPU/TGA films

The surface nano topographies of the SPI/TPU, SPI/MTPU, and SPI/MTPU/TGA films were examined by AFM as shown in Fig. 7. Ultra-thin sample sections were used, so the height mapping was relatively consistent $(\mathrm{a}, \mathrm{b}, \mathrm{c})$. Some epoxy resins had higher hardness caused by knife marks during the sectioning, but the middle parts were basically flat and unchanged, which ensured a high degree of uniformity among the three samples. The DMT modulus diagram (a1, b1, c1), shows a higher modulus and hardness in the sample area corresponding to an increase in brightness. These high-modulus areas may be attributed to the solidified structure of the film. A small amount of high-modulus and high-brightness components were unevenly interspersed in the dark area of the SPI/TPU film $\left(\mathrm{a}_{1}\right)$, indicating that SPI and TPU had similar moduli. SPI and TPU were only physically bound; no chemical bonds were generated. After SPI and MTPU were incorporated, the film modulus range expanded and the high modulus area grew more uneven, indicating that the epoxy group on MTPU reacted with SPI to improve the crosslinking structure. However, the low modulus of SPI did not allow for a hierarchical structure between SPI and MTPU. Light and dark areas were clearly observable and well-distributed in the SPI/MTPU/TGA films, which can be attributed to the reaction of TGA with SPI to form a crosslinking structure as a hard phase. This hard phase linked with MTPU as a soft phase to form a hierarchical structure with clearly alternating layers. The highest modulus of the SPI/MTPU/TGA film was $341 \%$ higher than that of SPI/TPU film.

The adhesion diagram reflects the adhesive force of each sample to the tip when a probe was pressed into it and allowed to bounce back [46], which is a representation of its hardness and softness. The diagram (a2, b2, c2) marks higher adhesion and hardness with relative brightness vs. darker parts. Adhesion was evenly distributed in the SPI/TPU film but there were some dark areas indicative of low adhesion (a1). After using SPI and MTPU to develop film, distinct light and dark areas emerged in the diagram (b2) indicating that the epoxy group on MTPU reacted with SPI to connect them, thus improving the crosslinking structure. When TGA was added to SPI/MTPU film, it enhanced the hard phase of the hierarchical structure to create visibly alternating hard and soft phases. The adhesion diagram of SPI/MTPU/TGA became uniform and rough with clearly definable brightness, which indicates where TGA reacted with SPI to form a crosslinking structure as a hard phase linked with MTPU as a soft phase to develop a hierarchical structure with a clearly alternating layers. 

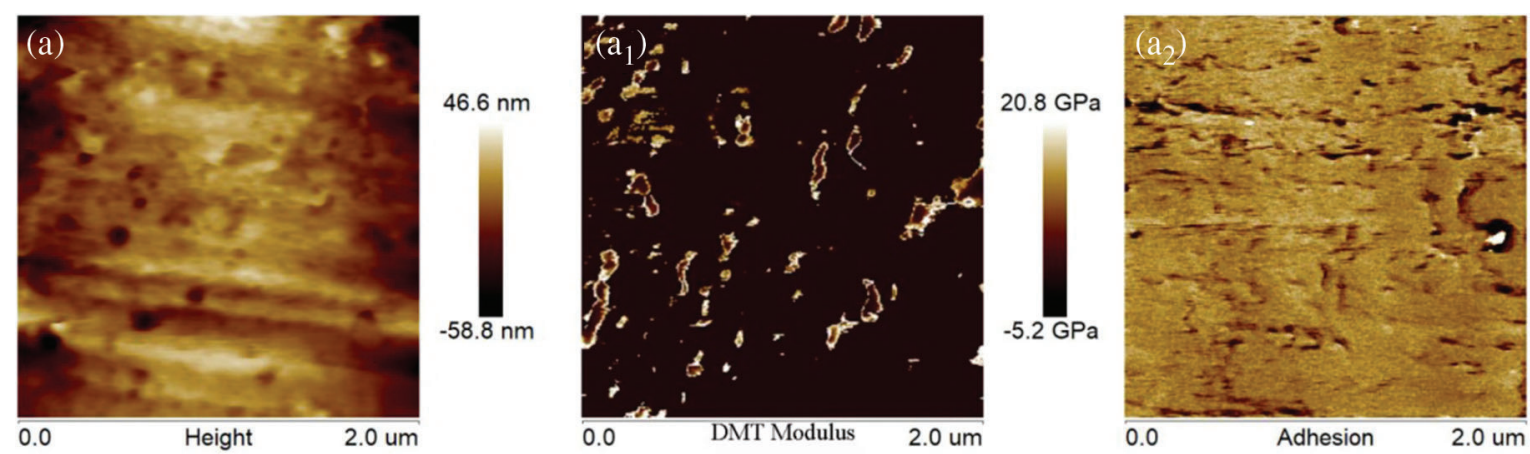

$19.4 \mathrm{nN}$
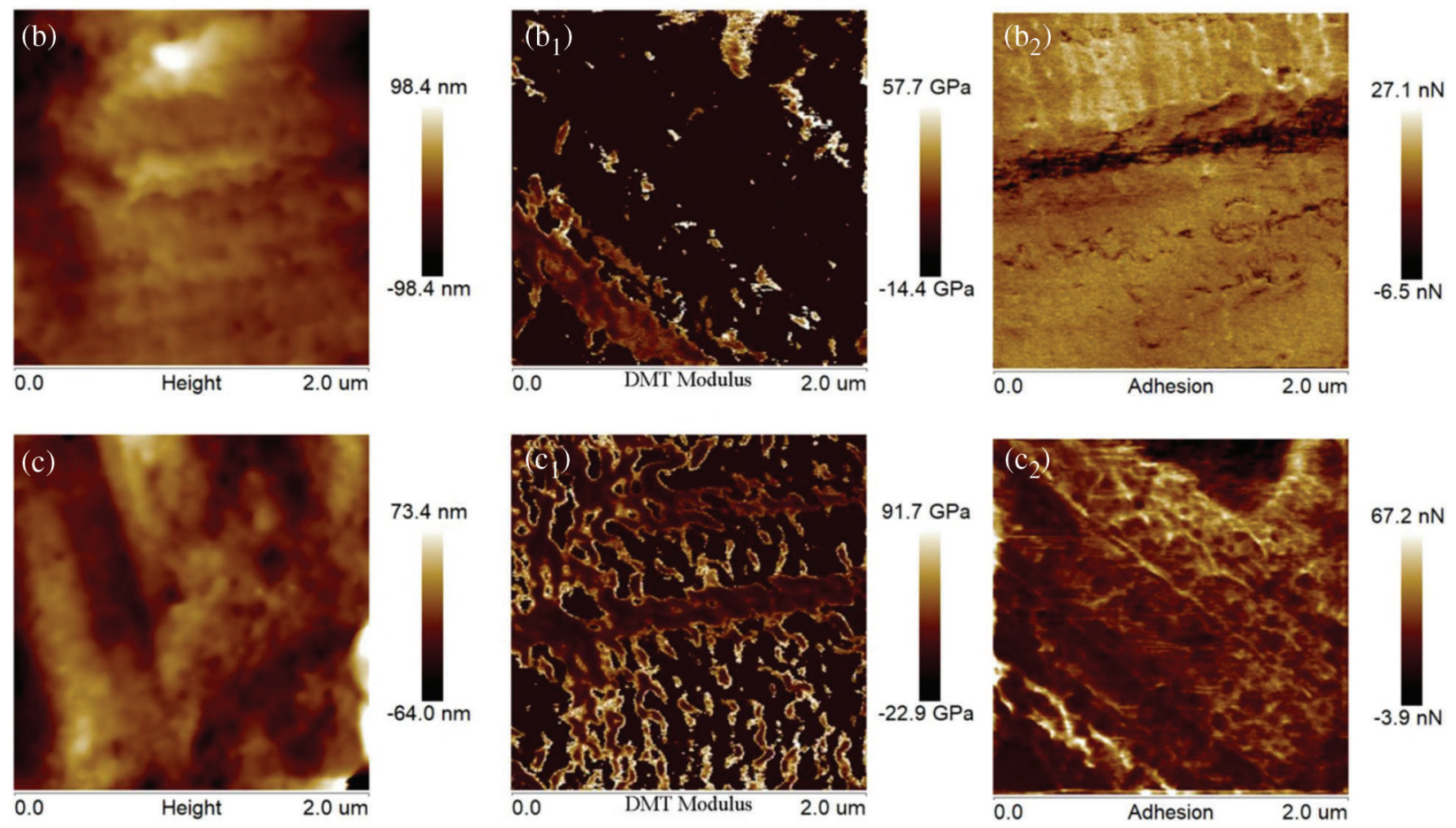

$67.2 \mathrm{nN}$

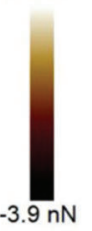

Figure 7: AFM images of SPI composite films a: SPI/TPU, b: SPI/MTPU, c: SPI/MTPU/TGA; (a) height, $\left(\mathrm{a}_{1}\right)$ DMT modulus, $\left(\mathrm{a}_{2}\right)$ adhesion

\section{Conclusion}

A novel bio-based film with a hierarchical structure inspired by natural nacre was developed in this study using soy protein and TPU. In this structure, soy protein is crosslinked by TGA as a hard phase and TPU as a soft phase as a surface modification to enhance the interface with the protein matrix while constructing alternating layers. The film showed significant increases in tensile strength and toughness without sacrificing elongation at break in comparison to other similar films without the proposed modification. TGA was successfully grafted to the TPU epoxide to form MTPU. Using TGA effectively crosslinked SPI to form a denser crosslinked network as MTPU reinforced the interface between the SPI matrix and TPU to develop a hierarchical structure with clearly distinguishable hard and soft phases. Compared with SPI/glycerin, the tensile strength and toughness of the SPI/MTPU/TGA composite film increased by $392 \%$ to $7.78 \mathrm{MPa}$ and $391 \%$ to $8.50 \mathrm{MJ} / \mathrm{m}^{3}$, respectively, thus indicating superior tensile strength and elongation break compared with previously reported films. This new hierarchical structure has significant potential to improve the performance and applicability of biological composite materials and polymers. 
Funding Statement: The authors are grateful to the financial support of the National Natural Science Foundation of China (32071702), and Beijing Forestry University Outstanding Young Talent Cultivation Project (2019JQ03004).

Conflicts of Interest: The authors declare that they have no conflicts of interest to report regarding the present study.

\section{References}

1. Chen, Q., Gao, K., Peng, C., Xie, H., Zhao, Z. K. et al. (2015). Preparation of lignin glycerol-based bis(cyclic carbonate) for synthesis of polyurethanes. Green Chemistry, 17, 4546-4551. DOI 10.1039/C5GC01340B.

2. González, A., Igarzabal, C. (2015). Nanocrystal-reinforced soy protein films and their application as active packaging. Food Hydrocolloids, 43, 777-784. DOI 10.1016/j.foodhyd.2014.08.008.

3. Koshy, R. R., Mary, S. K., Thomas, S., Pothan, L. A. (2015). Environment friendly green composites based on soy protein isolate-A review. Food Hydrocolloids, 50, 174-192. DOI 10.1016/j.foodhyd.2015.04.023.

4. Muthulakshmi, L., Rajini, N., Nellaiah, H., Kathiresan, T., Jawaid, M. et al. (2017). Preparation and properties of cellulose nanocomposite films with in situ generated copper nanoparticles using terminalia catappa leaf extract. International Journal of Biological Macromolecules, 95, 1064-1071. DOI 10.1016/j.ijbiomac.2016.09.114.

5. Tian, H., Yan, J., Rajulu, A. V., Xiang, A., Luo, X. (2017). Fabrication and properties of polyvinyl alcohol/starch blend films: Effect of composition and humidity. International Journal of Biological Macromolecules, 96, 518523. DOI 10.1016/j.jibiomac.2016.12.067.

6. Xie, D., Song, F., Zhang, M., Wang, X., Wang, Y. (2016). Roles of soft segment length in structure and property of Soy protein isolate/Waterborne polyurethane blend films. Industrial \& Engineering Chemistry Research, 55, 1229-1235. DOI 10.1021/acs.iecr.5b04185.

7. Zhu, M., Tan, C., Fang, Q., Gao, L., Sui, G. et al. (2016). High performance and biodegradable skeleton material based on Soy protein isolate for Gel polymer electrolyte. ACS Sustainable Chemistry \& Engineering, 4, 44984505. DOI 10.1021/acssuschemeng.6b01218.

8. Ciannamea, E. M., Espinosa, J. P., Stefani, P. M., Ruseckaite, R. A. (2018). Long-term stability of compressionmolded soybean protein concentrate films stored under specific conditions. Food Chemistry, 243, 448-452. DOI 10.1016/j.foodchem.2017.08.069.

9. Song, F., Tang, D. L., Wang, X. L., Wang, Y. Z. (2011). Biodegradable soy protein isolate-based materials: A review. Biomacromolecules, 12, 3369-3380. DOI 10.1021/bm200904x.

10. Park, S. K., Bae, D. H., Rheea, K. C. (2000). Soy protein biopolymers cross-linked with glutaraldehyde. Journal of the American Oil Chemists Society, 77, 879-884. DOI 10.1007/s11746-000-0140-3.

11. Bonham, S., Misra, M., Mohanty, A. K. (2011). Effect of Co-rotation and counter-rotation extrusion processing on the thermal and mechanical properties, and morphology of plasticized Soy protein isolate and poly(butylene succinate) blends. Macromolecular Materials and Engineering, 296, 788-801. DOI 10.1002/mame.201000404.

12. Tummala, P., Liu, W., Drzal, L. T., Mohanty, A. K., Misra, M. (2006). Influence of plasticizers on thermal and mechanical properties and morphology of Soy-based bioplastics. Industrial \& Engineering Chemistry Research, 45, 7491-7496. DOI 10.1021/ie060439 1 .

13. Klüver, E., Meyer, M. (2015). Thermoplastic processing, rheology, and extrudate properties of wheat, soy, and pea proteins. Polymer Engineering \& Science, 55, 1912-1919. DOI 10.1002/pen.24032.

14. Bozaci, E., Sever, K., Sarikanat, M., Seki, Y., Demir, A. et al. (2013). Effects of the atmospheric plasma treatments on surface and mechanical properties of flax fiber and adhesion between fiber-matrix for composite materials. Composites Part B: Engineering, 45, 565-572. DOI 10.1016/j.compositesb.2012.09.042.

15. Scherr, J., Parey, K., Klusch, N., Murphy, B. J., Balser, S. et al. (2017). Self-perforated hydrogel nanomembranes facilitate structural analysis of proteins by electron cryo-microscopy. ACS Nano, 11, 6467-6473. DOI 10.1021/ acsnano.7b03099.

16. Wang, Z., Zhao, S., Kang, H., Zhang, W., Zhang, S. et al. (2018). Mussel byssus-inspired engineering of synergistic nanointerfacial interactions as sacrificial bonds into carbon nanotube-reinforced soy protein/ 
nanofibrillated cellulose nanocomposites: Versatile mechanical enhancement. Applied Surface Science, 434, 10861100. DOI 10.1016/j.apsusc.2017.10.189.

17. Espinosa, H. D., Rim, J. E., Barthelat, F., Buehler, M. J. (2009). Merger of structure and material in nacre and bone-perspectives on de novo biomimetic materials. Progress in Materials Science, 54, 1059-1100. DOI 10.1016/j.pmatsci.2009.05.001.

18. Xie, H., Lai, X., Wang, Y., Li, H., Zeng, X. (2019). A green approach to fabricating nacre-inspired nanocoating for super-efficiently fire-safe polymers via one-step self-assembly. Journal of Hazardous Materials, 365, 125-136. DOI 10.1016/j.jhazmat.2018.10.099.

19. Meyers, M. A., McKittrick, J., Chen, P. Y. (2013). Structural biological materials: Critical mechanics-materials connections. Science, 339, 773-779. DOI 10.1126/science.1220854.

20. Gong, S., Ni, H., Jiang, L., Cheng, Q. (2017). Learning from nature: Constructing high performance graphenebased nanocomposites. Materials Today, 20, 210-219. DOI 10.1016/j.mattod.2016.11.002.

21. Oh, S. Y. (2008). Effect of residual stress on impact damage in a dissimilar laminated plate at a biaxial bending mode. International Journal of Automotive Technology, 9, 347-352. DOI 10.1007/s12239-008-0042-5.

22. Cui, Z., Zheng, Z., Su, C., Si, J., Wang, Q. et al. (2019). Porous 3-D thermoplastic polyurethane (TPU) scaffold modified with hydroxyapatite (HA) nanoparticles using an ultrasonic method. Journal of Materials Science, 54, 11231-11242. DOI 10.1007/s10853-019-03683-6.

23. Krol, P. (2007). Synthesis methods, chemical structures and phase structures of linear polyurethanes. properties and applications of linear polyurethanes in polyurethane elastomers, copolymers and ionomers. Progress in Materials Science, 52, 915-1015. DOI 10.1016/j.pmatsci.2006.11.001.

24. Yu, B., Tawiah, B., Wang, L. Q., Yuen, A. C., Zhang, Z. C. et al. (2019). Interface decoration of exfoliated MXene ultra-thin nanosheets for fire and smoke suppressions of thermoplastic polyurethane elastomer. Journal of Hazardous Materials, 374, 110-119. DOI 10.1016/j.jhazmat.2019.04.026.

25. Boyd, S. E., Bogetti, T. A., Staniszewski, J. M., Lawrence, B. D., Walter, M. S. (2018). Enhanced delamination resistance of thick-section glass-epoxy composite laminates using compliant thermoplastic polyurethane interlayers. Composite Structures, 189, 184-191. DOI 10.1016/j.compstruct.2018.01.062.

26. Weyand, S., Blattmann, H., Schimpf, V., Mülhaupt, R., Schwaiger, R. (2016). Structure-property-glass transition relationships in non-isocyanate polyurethanes investigated by dynamic nanoindentation. Materials Research Express, 3, 075019. DOI 10.1088/2053-1591/3/7/075019.

27. Xian, W. Q., Song, L., Liu, B. H., Ding, H. L., Li, Z. et al. (2018). Rheological and mechanical properties of thermoplastic polyurethane elastomer derived from $\mathrm{CO}_{2}$ copolymer diol. Journal of Applied Polymer Science, 135, 45974. DOI 10.1002/app.45974.

28. Connolly, J. M., Alferiev, I., Eidelman, N., Sacks, M., Palmatory, E. et al. (2005). Triglycidylamine crosslinking of porcine aortic valve cusps or bovine pericardium results in improved biocompatibility, biomechanics, and calcification resistance. American Journal of Pathology, 166, 1-13. DOI 10.1016/S0002-9440(10)62227-4.

29. Kim, D. H., Park, M. S., Choi, Y., Lee, K. B., Kim, J. H. (2018). Synthesis of PVA-g-pOEM graft copolymers and their use in highly permeable thin film composite membranes. Chemical Engineering Journal, 346, 739-747. DOI 10.1016/j.cej.2018.04.036.

30. Xu, F., Dong, Y., Zhang, W., Zhang, S., Li, L. et al. (2015). Preparation of cross-linked soy protein isolate-based environmentally-friendly films enhanced by PTGE and PAM. Industrial Crops and Products, 67, 373-380. DOI 10.1016/j.indcrop.2015.01.059.

31. Yang, S. Z., Madbouly, S., Schrader, J. A., Srinivasan, G., Grewell, D. et al. (2015). Characterization and biodegradation behavior of bio-based poly(lactic acid) and soy protein blends for sustainable horticultural applications. Green Chemistry, 17, 380-393. DOI 10.1039/C4GC01482K.

32. Zhao, S., Wen, Y., Wang, Z., Kang, H., Li, J. et al. (2018). Preparation and demonstration of poly(dopamine)triggered attapulgite-anchored polyurethane as a high-performance rod-like elastomer to reinforce soy proteinisolated composites. Applied Surface Science, 442, 537-546. DOI 10.1016/j.apsusc.2018.02.110. 
33. Xu, F., Zhang, W., Zhang, S., Li, L., Li, J. et al. (2015). Preparation and characterization of poly(vinyl alcohol) and 1, 2, 3-propanetriol diglycidyl ether incorporated soy protein isolate-based films. Journal of Applied Polymer Science, 132, 42578. DOI 10.1002/app.42578.

34. Garrido, T., Etxabide, A., Caba, K., Guerrero, P. (2017). Versatile soy protein films and hydrogels by the incorporation of $\beta$-chitin from squid pens (Loligo sp.). Green Chemistry, 19, 5923-5931. DOI 10.1039/ C7GC02982A.

35. Han, Y., Yu, M., Wang, L. (2018). Soy protein isolate nanocomposites reinforced with nanocellulose isolated from licorice residue: Water sensitivity and mechanical strength. Industrial Crops and Products, 117, 252-259. DOI 10.1016/j.indcrop.2018.02.028.

36. Kang, H., Song, X., Wang, Z., Zhang, W., Zhang, S. et al. (2016). High-performance and fully renewable Soy protein isolate-based film from microcrystalline cellulose via Bio-inspired poly(dopamine) surface modification. ACS Sustainable Chemistry \& Engineering, 4, 4354-4360. DOI 10.1021/acssuschemeng.6b00917.

37. Li, Y., Chen, H., Dong, Y., Li, K., Li, L. et al. (2016). Carbon nanoparticles/soy protein isolate bio-films with excellent mechanical and water barrier properties. Industrial Crops and Products, 82, 133-140. DOI 10.1016/j. indcrop.2015.11.072.

38. Martelli-Tosi, M., Assis, O. B. G., Silva, N. C., Esposto, B. S., Martins, M. A. et al. (2017). Chemical treatment and characterization of soybean straw and soybean protein isolate/straw composite films. Carbohydrate Polymers, 157, 512-520. DOI 10.1016/j.carbpol.2016.10.013.

39. Martelli-Tosi, M., Masson, M. M., Silva, N. C., Esposto, B. S., Barros, T. T. et al. (2018). Soybean straw nanocellulose produced by enzymatic or acid treatment as a reinforcing filler in soy protein isolate films. Carbohydrate Polymers, 198, 61-68. DOI 10.1016/j.carbpol.2018.06.053.

40. Adilah, M., Jamilah, Z. A., Nur Hanani, B. A. Z. (2018). Functional and antioxidant properties of protein-based films incorporated with mango kernel extract for active packaging. Food Hydrocolloids, 74, 207-218. DOI 10.1016/j.foodhyd.2017.08.017.

41. Xia, C., Zhang, S., Shi, S. Q., Cai, L., Garcia, A. C. et al. (2016). Property enhancement of soy protein isolatebased films by introducing POSS. International Journal of Biological Macromolecules, 82, 168-173. DOI 10.1016/j.ijbiomac.2015.11.024.

42. Xie, W. Y., Wang, F., Xu, C., Song, F., Wang, X. L. et al. (2017). A superhydrophobic and self-cleaning photoluminescent protein film with high weatherability. Chemical Engineering Journal, 326, 436-442. DOI 10.1016/j.cej.2017.05.170.

43. Yu, Z., Sun, L., Wang, W., Zeng, W., Mustapha, A. et al. (2018). Soy protein-based films incorporated with cellulose nanocrystals and pine needle extract for active packaging. Industrial Crops and Products, 112, 412419. DOI 10.1016/j.indcrop.2017.12.031.

44. Zhang, S., Xia, C., Dong, Y., Yan, Y., Li, J. et al. (2016). Soy protein isolate-based films reinforced by surface modified cellulose nanocrystal. Industrial Crops and Products, 80, 207-213. DOI 10.1016/j.indcrop.2015.11.070.

45. Jin, S., Li, K., Li, J. (2018). A general bio-inspired, novel interface engineering strategy toward strong yet tough protein based composites. Applied Surface Science, 447, 452-462. DOI 10.1016/j.apsusc.2018.03.073.

46. Pittenger, B., Erina, N., Su, C. (2014). Mechanical property mapping at the nanoscale using peakForce QNM scanning probe technique. Solid Mechanics \& Its Applications, 203, 31-51. DOI 10.1007/978-94-007-6919-9. 